\title{
Technical and vocational education and training (TVET) for young people in low- and middle- income countries: a systematic review and meta-analysis
}

\author{
Janice S Tripney ${ }^{1 *}$ and Jorge G Hombrados ${ }^{2}$
}

\footnotetext{
* Correspondence: j.tripney@ioe.ac.uk 'EPPI-Centre, Institute of Education, University of London, 18 Woburn Square, London, WC1H ONR, UK Full list of author information is available at the end of the article
}

\begin{abstract}
The world is facing a worsening youth employment crisis. In response, technical and vocational education and training (TVET) is back on the development agenda after years of neglect. This systematic review examined the evidence from studies evaluating the impacts of TVET interventions for young people in low- and middleincome countries (LMICs). The 26 included studies evaluated 20 different interventions, predominantly from Latin America. Meta-analyses of the effectiveness of TVET on five outcome measure categories were conducted. The overall mean effects on overall paid employment, formal employment, and monthly earnings were small, positive, and significant; however, significant heterogeneity was observed. Moderator analysis was performed in an attempt to explain between-study differences in effects. The overall paucity of research in this area, together with specific gaps and methodological limitations, affirm the need for strengthening the evidence base. Implications for policy, practice and research are discussed.
\end{abstract}

\section{Review}

\section{Introduction}

The global youth unemployment rate rose sharply between 2008 and 2009, from 11.8 to 12.7 per cent, reversing the pre-crisis trend of declining youth unemployment rates since 2002 (International Labour Organization 2011). By 2011, 74.8 million young people were unemployed. In some regions, young people are nearly three times as likely as adults to be unemployed; they are also more likely than older workers to be underemployed or work in the informal labour market, in poor quality jobs that require low levels of skills and offer limited socio-economic security, training opportunities, and working conditions (International Labour Organization 2012). Significant regional variation in youth unemployment exists; and, in many countries, young women are much more likely to be un/underemployed than young men (United Nations 2012). Over 40 per cent of all young people live on less than two US dollars a day, with youth in developing countries disproportionately among the working poor (International Labour Organization 2012). This enormous unlocked potential represents a substantial loss of opportunity for both individuals and society. 
One billion young people, the majority from LMICs, are predicted to reach employment age within the next decade (International Labour Organization 2012), compounding what are already severely limited opportunities for integrating youth into the labour market. With increasing policy importance now placed on higher-order skills and their central role in the global knowledge-based economy, comes a renewed focus on the potential of TVET to equip youths with the abilities to seize available work opportunities, and, in turn, impact upon global poverty and social stability (African Union 2007; King and Palmer 2010; Péano et al. 2008; United Nations Educational, Scientific and Cultural Organization 2010, 2012). Neglected by the World Bank and other donor agencies during much of the 1980s and 1990s, there has been growing investment in TVET since 2000. Deciding which programmes to implement requires an understanding not only of which models are effective, but for whom they are effective. Collecting evidence from studies that have analysed these issues is crucial for purposes of policy-making.

\section{Technical and vocational education and training (TVET)}

The term TVET, as used in this systematic review, follows the definition used by UNESCO as "those aspects of the educational process involving, in addition to general education, the study of technologies and related sciences and the acquisition of practical skills, attitudes, understanding and knowledge relating to occupation in various sectors of economic life". It incorporates: technical education, vocational education, vocational training, on-the-job training, and apprenticeship training (or any combination thereof).

\section{Prior reviews of TVET}

Although a number of prior reviews have summarised the existing research in this area (see, for example, Angel-Urdinola et al. 2010; Betcherman et al. 2004; Betcherman et al. 2007; Card et al. 2010; Fares and Puerto 2009; Greenberg et al. 2003; Katz 2008; Kluve 2006; Kluve and Schmidt 2002; Puerto 2007; Stavreska 2006; Van Adams 2007), there are a number of limitations to these reviews. Some contain evidence from high-income countries only; others, whilst broader in geographical scope, do not focus specifically on developing countries, TVET, or young people. Very few existing reviews are based on a comprehensive, systematic search for literature, and almost all take either a traditional narrative approach to synthesis or use vote-counting methods where conclusions regarding effective interventions are made based on the number of studies found to demonstrate significant positive results. None of the previous reviews that specifically focus on TVET for youth in LMICs have computed effect sizes for the included studies or examined variability in effects by study, participant or intervention characteristics. These are problems that this review aims to remedy, thereby adding value to the existing body of research on this topic.

\section{Purpose of the present study}

This review sought to improve upon prior work by systematically examining the evidence base to provide a clearer picture of the types of TVET interventions being used to improve employment prospects for youth in LMICs, to identify the overall effectiveness of TVET, to examine whether study, participant and intervention characteristics 
help to explain variability in intervention effects, and to identify areas in which more research needs to be conducted. An extended version of this article is available as a technical report published in the Campbell Collaboration library (Tripney et al. 2013).

\section{Methods}

Systematic review methodology was utilised for all aspects of the search, selection and coding of studies. The review was conducted in accordance with Campbell Collaboration procedures and guidelines on systematic review methods, available at http:// campbellcollaboration.org/. Full details about the methods for this review can be found in the technical report, and review protocol (Tripney et al. 2012).

\section{Eligibility criteria}

Eligibility was restricted to studies that: were conducted in LMICs; were reported between 2000 and 2011; evaluated the impact of a TVET intervention; investigated outcomes for youth aged 15-24 years; included at least one quantifiable measure of employment or employability (broadly defined); and used an experimental or rigorous quasi-experimental design (such as the use of propensity scores to match on pre-tests and/or relevant demographic characteristics or regression analysis to control for differences between groups). Single group pre-post test studies were not eligible. No language or publication status restrictions were applied.

The conceptual definition of TVET used in this review cuts across education level, type of learning arrangement, mode of delivery, setting, and type of provider/regulator. It includes provision of (i) initial training for young people from the age of 15/16 years after compulsory school, but prior to entering work; (ii) continuing education and training for adults in the labour market leading to personal, flexible and/or vocational competencies; and (iii) training for unemployed persons currently available for and seeking work (including retraining for those made redundant). Single- and multiservice TVET interventions were eligible for inclusion in the review, as were interventions delivered for any length of time or frequency. LMICs were defined according to World Bank classification of economies (in effect 1 July 2011 until 30 June 2012).

\section{Literature search and strategy}

The review recognised the importance of using a comprehensive and diverse search strategy to locate all qualifying published and unpublished studies (Papaioannou et al. 2009; Schucan Bird and Tripney 2011). First, 10 major bibliographic databases were electronically searched (including ASSIA, Econlit, ERIC, IBSS, Medline, PsycINFO, and SSCI). Searches within each database combined controlled vocabulary and natural language terms, with appropriate wildcards, for three concepts: TVET, employment, and study design. Second, specialist databases and library catalogues were searched, including grey literature, regional and topic-specific sources. Third, the websites of government agencies, research centres, foundations, professional associations, and other relevant organisations were searched. Fourth, the reference lists of previous reviews and included studies were checked. Fifth, citation searches of included studies were conducted. Sixth, information about additional relevant studies was requested from authors of included studies and other key experts in the field. 
Data extraction and critical appraisal

Data were independently extracted from all included studies by pairs of reviewers using a coding tool specifically designed for this review. Studies were quality assessed using a tool developed specifically for assessing risk of bias in experimental and quasi-experimental designs based on statistical methods (Hombrados and Waddington 2012).

\section{Analysis}

Where data allowed, effect sizes were computed for each study and random-effects inverse-variance weighted meta-analytic methods were used to synthesise the evidence. We followed Petrosino et al. (2012) in the use of standardised mean differences (SMDs) for synthesising both continuous and dichotomous outcomes. The different formulas used in calculating effect sizes are detailed in the full technical report. The included studies were analysed by outcome and Hedges' $g$ effect sizes were reported. To visibly examine between-study variability in the effect size estimates, forest plots were used to display the estimated effect sizes from each study along with their 95 per cent confidence intervals (CIs). Heterogeneity was explored using both the $\mathrm{Q}$ test and the $\mathrm{I}^{2}$ index (Deeks et al. 2001; Higgins and Green 2011). Moderator analyses were performed to examine possible reasons for variability in effects. Due to the small number of available studies, an analogue to the ANOVA analysis (univariate) approach was used (Lipsey and Wilson 2001). The categorical variables which identified the sub-groups used in this exercise were specified in advance.

\section{Results}

Size of literature reviewed

Of the 8072 articles identified using the electronic search, 145 were deemed potentially relevant on the basis of title and abstract and the full papers were retrieved for a full text review. The full papers of a further 76 items identified through the non-database search were also manually examined. This process resulted in a total of 30 different studies, described in 55 separate publications, being identified as meeting the eligibility criteria. Of these, 26 studies were included in the review. ${ }^{a}$ The study search and selection process is detailed in Figure 1.

\section{Descriptive analysis}

Publication dates of the 26 included studies ranged between 2001 and 2011, and over three-quarters were published as technical reports. Three studies were randomised experiments and 23 studies used a quasi-experimental design (QED). The QED evaluations used different econometric techniques to address selection bias and net out the impacts of other factors, most commonly propensity score matching (Rosenbaum and Rubin 1983). The majority of study samples included both male and female participants, and a single study focused exclusively on young women. The risk of bias assessments resulted in five studies graded medium quality (Attanasio et al. 2011; Card et al. 2011; Chong and Galdo 2006; Hicks et al. 2011; Espinoza 2010), 10 graded low/medium (Acero et al. 2011; Aedo and Nuñez 2004; Aedo and Pizarro 2004; Analítica Consultores 2006; Chong et al. 2008; Díaz and Jaramillo 2006; Elías et al. 2004; Ibarraran and Rosas-Shady 2006; Jaramillo et al. 2007; Ñopo et al. 2007) and 11 graded low (Alzuá 


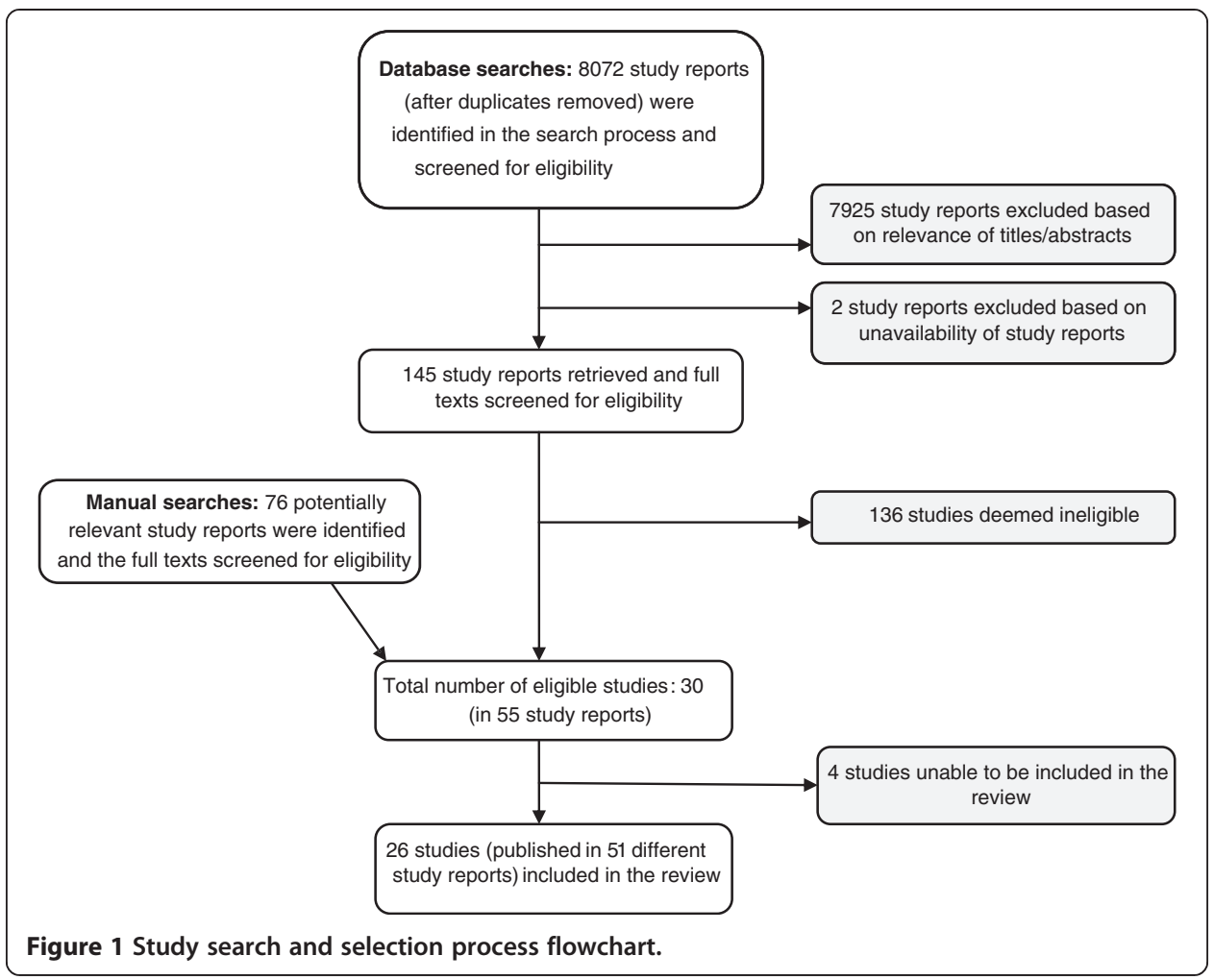

and Brassiolo 2006; Alzúa et al. 2007; Benus et al. 2001; Bidani et al. 2002; Chun and Watanabe 2011; Delajara et al. 2006; Dmitrijeva 2009; López-Acevedo 2003; Medina and Nuñez 2005; Mensch et al. 2004; van Gameren 2010). ${ }^{\text {d }}$

Twenty different TVET programme interventions were evaluated. Settings include 10 upper-middle income countries (Argentina; Bosnia and Herzegovina; Brazil; Chile; China; Colombia; Dominican Republic; Latvia; Mexico; Panama and Peru); two lowermiddle income countries (India and Bhutan); and one low-income country (Kenya). Twelve programmes were specifically targeted at youth. The majority were targeted at disadvantaged populations, based on criteria such as household income, education level, and employment experience. A few were occupation- rather than age-focused (targeting, for example, demobilised soldiers or unemployed former employees of stateowned enterprises). A small number of interventions were directed exclusively at either urban or rural residents.

The 20 TVET interventions consisted of one or more of the different models or approaches to vocational skills development (see Table 1). The different types of TVET are not evenly represented, however; for instance, no apprenticeship training programmes were evaluated and a very small number of studies focused on technical education or vocational education. Many of the interventions in the included studies were complex, multi-component programmes. Alongside TVET-related training, some programmes incorporated labour mediation services (such as job readiness skills), some included training specifically for self-employment and some included other types of training (such as basic skills). However, the largest category of multi-component programme involved components consisting of different types of TVET. There were 
Table 1 Main intervention characteristics

\begin{tabular}{lr}
\hline Characteristic & N \\
\hline Type/model of TVET & \\
\hline Technical education & 2 \\
\hline Vocational education & 1 \\
\hline Vocational training & 16 \\
\hline On-the-job training & 14 \\
\hline Apprenticeship training & 0 \\
\hline Key programme features & 9 \\
\hline MC: sequential TVET components (i.e., two-phase TVET models) & 6 \\
\hline MC: incorporates labour intermediation services & 4 \\
\hline MC: incorporates training specifically for self-employment & 3 \\
\hline MC: incorporates non-TVET-related training (e.g., life skills) &
\end{tabular}

Notes. *programme as a whole or programme component; MC - multi-component.

nine two-phase TVET interventions, most of which combined theoretical and practical training, usually in the format of classroom-based vocational training followed by a period of on-the-job training to provide beneficiaries with work experience. These interventions typically focused on short-term semi-skilled training in specific occupations demanded in the private sector.

Primary study authors often did not provide all the necessary data for computing effect sizes. It was possible to calculate at least one effect size for 10 of the studies included in the review (Acero et al. 2011; Aedo and Nuñez 2004; Aedo and Pizarro 2004; Attanasio et al. 2011; Card et al. 2011; Elías et al. 2004; Espinoza 2010; Hicks et al. 2011; Ibarraran and Rosas-Shady 2006; Medina and Nuñez 2005). The findings from these studies were statistically combined using meta-analytic techniques.

\section{Overall mean effects of interventions}

The overall mean effect sizes for five outcomes are presented in Table 2. For three outcomes, an overall positive and statistically significant effect on TVET on youth was found: overall paid employment $(g=0.134 ; 95 \%$ CI [0.024, 0.243]); formal employment $(g=0.199 ; 95 \%$ CI $[0.055,0.344])$; and earnings $(g=0.127 ; 95 \%$ CI $[0.043,0.21])$. For working hours worked, the overall effect was also positive, but non-significant $(g=0.043 ; 95 \%$ CI $[-0.017,0.104])$. In contrast, the overall effect on self-employment earnings was negative, and non-significant $(g=-0.025 ; 95 \% \mathrm{CI}[-0.11,0.061]) .^{\mathrm{b}}$

Table 2 Overall mean effect size and heterogeneity statistics

\begin{tabular}{lllllll}
\hline & Hedges' $\boldsymbol{g}$ & $\mathbf{9 5 \%} \mathbf{C l}$ & $\mathbf{k}$ & $\mathbf{Q}$ & $\mathbf{I}^{\mathbf{2}}$ & tau $^{\mathbf{2}}$ \\
\hline Overall paid employment & 0.134 & $0.024,0.243$ & 8 & $23.8^{*}$ & $70.6 \%$ & 0.0153 \\
\hline Formal employment & 0.199 & $0.055,0.344$ & 5 & $11.1^{*}$ & $63.9 \%$ & 0.0131 \\
\hline Earnings & 0.127 & $0.043,0.21$ & 9 & $25.5^{*}$ & $68.6 \%$ & 0.00815 \\
\hline Self-employment earnings & -0.025 & $-0.11,0.061$ & 2 & 0.206 & $0 \%$ & 0 \\
\hline Weekly hours worked & 0.043 & $-0.017,0.104$ & 6 & 1.8 & $0 \%$ & 0 \\
\hline
\end{tabular}

Note. ${ }^{*} p<0.05$. 


\section{Analysis of homogeneity}

For three outcomes (overall paid employment, formal employment, and earnings) the grand mean provides some evidence that the TVET interventions were, on average, effective; although, effects are generally small and difficult to detect. Furthermore, in each case the result of the statistical test for homogeneity was statistically significant $(\mathrm{Q}=23.8, \mathrm{p}<$ $0.05 ; \mathrm{Q}=11.1, \mathrm{p}<0.05 ; \mathrm{Q}=25.5, \mathrm{p}<0.05$ ), indicating that studies disagreed on the magnitude of effect. Our next step was to explore the reasons for this variability between studies.

\section{Analysis of moderator effects}

Moderator analyses were performed to examine independent variables that may be contributing to the heterogeneity. The results are presented in Table 3.

\section{Relationship of study characteristics to effect size}

Two factors potentially associated with treatment effect were examined: study quality and length of follow up (i.e., timing of outcome measurement). As there were no high quality studies included in the review, studies rated medium quality were compared with those rated low or low-medium. ${ }^{\mathrm{c}}$ Short-term treatment effects (measured at approximately six months) were compared with medium-term effects (measured at approximately 12 months). The low quality studies were found to have consistently larger mean effects than the medium quality studies; and, for two outcomes, differences in mean effects observed between studies according to study quality were statistically significant: paid employment $\left(\mathrm{Q}_{\mathrm{b}}=6.49, \mathrm{p}=0.0108\right)$; formal employment $\left(\mathrm{Q}_{\mathrm{b}}=10.6, \mathrm{p}=0.0012\right)$. Although studies that measured short-term treatment effects consistently had slightly larger mean effects than studies in the mediumterm follow up group, no statistically significant relationship between length of follow up and treatment effect was observed for any of the outcomes for which we had data.

\section{Relationship of participant characteristics (gender) to effect size}

For one of the five outcome categories (weekly hours), statistically significant differences in mean treatment effects were observed between studies according to gender $(\mathrm{Qb}=10.1 ; \mathrm{p}=0.00151)$. Treatment effects for female youth were positive $(g=0.16$; $95 \%$ CI $[0.04,0.28])$, while those for male youth were negative $(g=-0.09 ; 95 \%$ CI $[-0.2$, $0.01])$. However, male youth participation in TVET demonstrated effects that were not statistically different from zero, lessening our confidence in this result.

\section{Relationship of intervention characteristics (type) to effect size}

Slight differences in mean effects between two-phase models of TVET and other models were observed, with two-phases usually, but not always, producing the larger effects. However, these differences were not statistically significant.

\section{Conclusions}

This review improves upon prior work by statistically synthesising TVET intervention research, strengthening the evidence base on which current policies and practices can draw. However, the nature of the available evidence, and limitations in the review itself, are such that drawing strong inferences from the results of the analyses is not recommended and considerable caution should be used when interpreting and applying the findings of the review. 
Table 3 Moderator analysis results for categorical factors

\begin{tabular}{|c|c|c|c|c|}
\hline Outcome & Factor & $\mathrm{Q}_{\mathrm{b}}$ & Mean ES & $95 \% \mathrm{Cl}$ \\
\hline \multirow[t]{12}{*}{ Overall paid employment } & Study quality & $6.49^{*}$ & & \\
\hline & Medium & & 0.06 & $-0.01,0.12$ \\
\hline & Low & & 0.25 & $0.12,0.38$ \\
\hline & Length of follow-up & 0.273 & & \\
\hline & Medium-term & & 0.12 & $0,0.24$ \\
\hline & Short-term & & 0.18 & $0,0.36$ \\
\hline & Intervention type & 1.43 & & \\
\hline & Two-phase models & & 0.16 & $0.04,0.28$ \\
\hline & Other models & & 0.01 & $-0.2,0.22$ \\
\hline & Gender & 2.1 & & \\
\hline & Female & & 0.1 & $0,0.2$ \\
\hline & Male & & 0.01 & $-0.08,0.09$ \\
\hline \multirow[t]{3}{*}{ Formal employment } & Study quality & $10.6^{*}$ & & \\
\hline & Medium & & 0.12 & $0.05,0.19$ \\
\hline & Low & & 0.37 & $0.24,0.5$ \\
\hline \multirow[t]{12}{*}{ Earnings } & Study quality & 0.204 & & \\
\hline & Medium & & 0.12 & $0.05,0.18$ \\
\hline & Low & & 0.15 & $0.01,0.3$ \\
\hline & Length of follow-up & 0.186 & & \\
\hline & Medium-term & & 0.14 & $0.05,0.24$ \\
\hline & Short-term & & 0.22 & $-0.13,0.58$ \\
\hline & Intervention type & 0.397 & & \\
\hline & Two-phase models & & 0.14 & $0.04,0.23$ \\
\hline & Other models & & 0.06 & $-0.15,0.27$ \\
\hline & Gender & 1.26 & & \\
\hline & Female & & 0.14 & $0.08,0.21$ \\
\hline & Male & & 0.09 & $0.02,0.16$ \\
\hline \multirow[t]{3}{*}{ Self-employment earnings** } & Gender & 1.27 & & \\
\hline & Female & & 0.03 & $-0.08,0.13$ \\
\hline & Male & & -0.06 & $-0.18,0.05$ \\
\hline \multirow[t]{12}{*}{ Weekly hours worked in paid employment } & Study quality & 1.41 & & \\
\hline & Medium & & 0.02 & $-0.05,0.09$ \\
\hline & Low & & 0.1 & $-0.01,0.22$ \\
\hline & Length of follow-up & 0.109 & & \\
\hline & Medium-term & & 0.04 & $-0.03,0.1$ \\
\hline & Short-term & & 0.07 & $-0.1,0.24$ \\
\hline & Intervention type & 0.068 & & \\
\hline & Two-phase models & & 0.04 & $-0.02,0.1$ \\
\hline & Other models & & 0.07 & $-0.14,0.28$ \\
\hline & Gender & $10.1^{*}$ & & \\
\hline & Female & & 0.16 & $0.04,0.28$ \\
\hline & Male & & -0.09 & $-0.2,0.01$ \\
\hline
\end{tabular}

Notes. ${ }^{*} \mathrm{p}<0.05 ;{ }^{* *}$ only medium quality studies used in this group.

Despite renewed investment in TVET and increased pressure for evidence-based decision-making, there remains an overall scarcity of research in this area and specific knowledge gaps. The interventions included in this systematic review are not 
representative of all TVET programmes in existence. Studies were undertaken in a relatively small number of counties, predominantly in Latin America and the Caribbean. Some types of TVET are poorly represented in the review; for example, no studies examined the effectiveness of apprenticeship training. The quality of the existing evidence base is also a concern. Only three RCTs were identified, and methodological and reporting shortcomings of the included studies were such that none provided high quality evidence to help answer the review questions.

Overall, interventions included in the meta-analyses were found to demonstrate a significant, though small, positive effect on a limited range of labour market outcomes: overall paid employment $(g=0.134 ; 95 \%$ CI [0.024, 0.243]); formal employment $(g=$ 0.199 ; 95\% CI [0.055, 0.344]); and monthly earnings ( $g=0.127 ; 95 \%$ CI $[0.043,0.21])$. However, the observed heterogeneity was also significant, indicating that different studies point to somewhat different conclusions. Attempts to explain the heterogeneity in overall mean effects suggest that methods matter. The low quality studies have consistently larger mean effects than the medium quality studies. For two outcomes, evidence of a statistically significant relationship between study quality and effect size magnitude suggest that the overall mean effect may be inflated and that our conclusions about treatment effect should be based only on those studies rated medium quality: paid employment ( $g=0.06$; $95 \%$ CI $[-0.01,0.12])$; formal employment $(g=0.12$; $95 \%$ CI $[0.05$, $0.19])$. Treatment effects for both self-employment earnings and weekly hours worked were non-significant. On the whole, the other independent variables that were tested were unable to explain variability in effects. Length of follow up did not demonstrate a significant relationship with treatment effect. Two-phase TVET interventions (classroom-based vocational training followed by on-the-job training) produced statistically similar effects to other TVET models. Gender may have some influence, as an increase in the number of weekly hours worked by youth following participating in TVET appears to be driven by the effect on young women. It is important to note, however, that due to an insufficient number of studies reporting relevant data, only some of the moderator analyses that had been planned a priori could be performed. Furthermore, due to the very small number of studies for most of the variables tested, and thus low statistical power, we may not have been able to detect moderator effects that may indeed be present. In addition, there may be other moderating variables that either were not tested in this study or measured in the primary reports, such as implementation fidelity, whether the intervention was theoretically informed, and so on, which could account for the differences in effects between studies.

While a key strength of this study is its application of systematic review principles to improve upon prior work. There are several important limitations to this review that should be acknowledged. First, not all eligible studies are included in the meta-analysis. Second, the methods for calculating comparable effect sizes from studies using complex econometrics methods, as used in this review, are under-developed and require further research (for a complete discussion, see Becker and Wu 2007; Duvendack et al. 2012; Lipsey and Wilson 2001). Third, no high quality studies were identified and some of the methodological concerns associated with those that were included may mean that the studies have yielded biased estimates of treatment effect. All conclusions from the current review are therefore sensitive to the possibility that the results from the meta-analyses may be over- or under-estimating the effects of TVET on the outcome variables of interest. 
Limitations notwithstanding, this systematic review provides some evidence to support the claim that participation in TVET improves the labour market situation of youth in LMICs, on average, when compared to youth who do not participate, with the strength of the evidence strongest for formal employment and monthly earnings. Thus, it is reasonable to conclude that it is worthwhile to continue investment in TVET provision. Although, statistically, the effects of TVET on youth may be small, even a slight increase in the employment rate, for example, could potentially translate into fairly large numbers of young people entering the labour market, especially where programmes are delivered nationally. Through its use of statistical meta-analysis, this review has improved upon previous work; nevertheless, there are two main related areas of likely disappointment for policymakers and programme implementers. First, not only were the observed effects generally small and difficult to detect, the review does not provide conclusive evidence of the effectiveness of TVET on youth employment outcomes. This suggests an urgent need to improve the rigour of the evidence base, and will require policymakers, practitioners and other relevant stakeholders engaging critically with the barriers to effective research production and dissemination in this area. The commissioning of RCTs and robust QEDs is crucial for generating evidence capable of supporting causal claims. To improve potential generalisability, it is also important that appropriate support, financial and otherwise, is given to rigorous outcome research on all types of TVET that have been implemented internationally for young people, and in a broader range of geographical settings than covered by the current evidence base. A cost-benefit analysis was outside the scope of the current review; however, attention should be given to the collection of data regarding the costs of TVET interventions, and examinations of cost-effectiveness should be a priority in future impact evaluations and systematic reviews. Second, the available evidence does not allow recommendations to be made for, or against, investments in a particular model of TVET. Although claims have been made in the literature and media for the success or effectiveness of a particular format of TVET widely implemented in Latin America and the Caribbean, the evidence from this systematic review suggests that such claims are premature. In the absence of evidence in support of any one model or approach to vocational skills development, it seems reasonable in the meantime for policymakers and other stakeholders to select the least costly, most culturally acceptable, and/or most easily implemented programmes, while at the same time becoming good consumers of evidence and working towards the strengthening of the evidence base on TVET. This review has demonstrated that not only is there is a clear need for additional primary research in this area, but that more of the same will not suffice. The methodological shortcomings of the current evidence base, and specific knowledge gaps, suggest a number of future research priorities. These are summarised in Table 4.

\section{End notes}

${ }^{a}$ Four eligible Spanish-language studies could not be included in the review. Of these, one study was judged as meeting the review selection criteria on the basis of detailed descriptions in previous literature reviews, but efforts to obtain a copy of the publication were unsuccessful. The three remaining eligible non-English language studies were not included in the review due to exhaustion of financial resources. All four studies 
Table 4 Summary of recommendations to improve study quality and fill research gaps

Issue
Lack of rigorous study designs
Evaluated interventions not representative of all
TVET programmes in existence

Inadequate descriptions of interventions

Lack of studies testing intervention components

Lack of reported information on all key variables

Inconsistency in defining, measuring and reporting outcomes

Lack of studies assessing long-term outcomes

Lack of studies assessing intermediate outcomes

Lack of studies assessing net employment outcomes

Inadequate reporting of data needed to compute effect sizes

Inadequate reporting of information needed for assessments of risk of bias and study replication

Under-development of methods for calculating comparable effect sizes from studies using complex econometrics methods

Under-development of quasi-experimental evaluation designs involving complex econometric methods Recommendation

Additional studies using rigorous designs are needed, preferably with random assignment

Additional studies are needed to evaluate outcomes of apprenticeship programmes, technical education, and vocational education. This is a further need for additional TVET studies from LMICs in Asia, Africa, and Europe.

Provide a detailed description of the intervention (including any components) in such as way that the intervention could be replicated (e.g., duration and frequency of sessions, curriculum, stipends, and trainee accreditation).

Analysis of the effects of individual intervention components is needed in future studies.

Provide adequate descriptions of the study sample (e.g., age, race, SES, gender, and \% with work experience at baseline) and other relevant variables that may influence treatment effects (e.g., whether the intervention was theoretically underpinned, and implementation issues).

Improve descriptions of employment-related outcome measures, and agree on definitions. Consistently and clearly measure and report study outcomes. Where applicable, measure and report outcomes separately (for example, differentiate part-time and full-time employment).

Measure and report outcomes related to employment at multiple time points following the intervention, beyond 18 months and preferably over several years.

Studies need to examine relevant intermediate outcomes (such as work attitudes) via consideration of the theory of change underpinning the intervention.

Measure and report net employment outcomes to demonstrate whether job creation is additional or not. Explore whether this is possible to do with sufficiently powered cluster designs.

Report relevant information for all outcomes, such as the sample size, mean and standard deviation (pooled, treatment and/or control) and frequencies/probabilities of an event occurring in each of the groups (as opposed to the difference between the groups), regardless of whether the results of statistical tests for that variable were statistically significant, or the results of other analyses are presented.

Provide a detailed description of the study in such a way that allows (a) confident judgements to made about the trustworthiness of the reported analyses and (b) replication of the study.

Further research on these methods is required.

Develop methods for measuring (and ultimately reducing) the bias incurred by the use of such techniques.

evaluated ProJoven, a Peruvian programme that was evaluated by a number of studies that were included in the review.

b A preliminary assessment of the 'direction of effects' of the 16 studies not included in the meta-analyses suggests that these studies generally support the meta-analytic findings. 
${ }^{c}$ For this exercise, all of these studies were grouped together into a single category labelled low.

d One study (Espinoza 2010) was graded medium quality overall; however, individual assessments for the different outcome categories varied. For employment outcomes, this study was graded as proving medium quality evidence; for monthly earnings, the grading was low/medium.

e World Bank country classifications have been revised twice since the conduct of this review, and Chile and Latvia are currently ranked as high income economies.

\author{
Abbreviations \\ LMIC: Low- and middle-income country; QED: Quasi-experimental design; RCT: Randomised controlled trial \\ SMD: Standardised mean difference; TVET: Technical and vocational education and training.
}

\title{
Competing interests
}

The authors declare that they have no competing interests.

\section{Authors' contributions}

JT conceived and designed the study; collected, analysed and interpreted the data; and drafted the manuscript. JH participated in the coordination of the study and data acquisition; advised on the statistical analysis and interpretation of data; and revised the manuscript. Both authors read and approved the final manuscript.

\section{Authors' information}

JT is a lecturer in Social Policy, based at the EPPI-Centre (Evidence for Policy and Practice Co-ordinating Centre), Social science Research Unit, Institute of Education, University of London. JH is a research analyst at J-PAL (Abdul Latif Jameel Poverty Action Lab), based at its regional office in Latin America at the Pontificia Universidad Católica de Chile.

\section{Acknowledgements}

This manuscript arose from a systematic review commissioned in 2011 by the Australian Agency for International Development (AusAID), in response to the International Initiative for Impact Evaluation (3ie) systematic reviews call 3. JT was the grant holder and principal investigator. JH participated in the full review on an un-funded basis. JT and JH wish to acknowledge the contributions of those who helped in the creation of the full review: Mark Newman was involved in data collection and advised on the statistical analysis; Kimberley Hovish, Chris Brown, Katarzyna Steinka-Fry and Eric Wilkey participated in the acquisition of data. Special thanks are due to Sandra Jo Wilson, editor of the Education Coordination Group (ECG), for her guidance throughout the initial project. The funding agency informed the scope and development of the full review. The preparation of this manuscript was unfunded, and the funding agency had no role in the writing of this manuscript, or the decision to submit the manuscript for publication. The opinions expressed in this manuscript are those of the authors and do not necessarily reflect those of the funding agency. The full version of the review is published in the Campbell library (http://www.campbellcollaboration.org/lib/project/227/) and the 3ie database of systematic reviews (http://www.3ieimpact.org/en/evidence/systematic-reviews/details/152/).

\section{Author details}

${ }^{1}$ EPPI-Centre, Institute of Education, University of London, 18 Woburn Square, London, WC1H ONR, UK. ${ }^{2}$ Abdul Latif Jameel Poverty Action Lab (J-PAL), Pontificia Universidad Católica de Chile, Av. Vicuna MacKenna, Santiago 4860, Chile.

Received: 11 November 2013 Accepted: 12 November 2013

Published: 20 December 2013

\section{References}

Acero C, Alvarado M, Bravo D, Contreras D, Ruiz-Tagle J (2011) Evaluación de impacto del Programa Jóvenes al Bicentenario para la cohorte de participantes en el Año 2008. http://www.pnud.cl/proyectos/Documentos\%20de\% 20proyectos/2011/Informe\%20Evaluaci\%C3\%B3n\%20Impacto\%20JB_FINAL.pdf. Accessed 25 Oct 2013

Aedo C, Nuñez S (2004) The impact of training policies in Latin America and the Caribbean: The case of Programa Joven (Research Network Working Paper \#R-483). Inter-American Development Bank, Washington

Aedo C, Pizarro M (2004) Rentabilidad económica del programa de capacitación laboral de jóvenes 'Chile Joven'. INACAP and Mideplan, Santiago de Chile

African Union (2007) Strategy to revitalize technical and vocational education and training (TVET) in Africa. Pape presented at the Meeting of the Bureau of the Conference of Ministers of Education of the African Union (COMEDAF I+), Addis Ababa, May 2007. http://info.worldbank.org/etools/docs/library/243614/TVET\%20Strategy\% 20in\%20Africa.pdf. Accessed 25 Oct 2013

Alzuá ML, Brassiolo P (2006) The impact of training policies in Argentina: An evaluation of Proyecto Joven (Working Paper: OVE/WP-15/06). Inter-American Development Bank, Washington

Alzúa ML, Nahirñak P, Alvarez De Toledo B (2007) Evaluation of Entra 21 using quantitative and qualitative data. Qsquared Working Paper No. 41. University of Toronto Centre for International Studies, http://www.trentu.ca/ids/documents/Q2_WP41_Alzua_etal.pdf. Accessed 25 Oct 2013

Analítica Consultores (2006) Estudio de evaluacion de la estrategia Bécate. Secretaría del Trabajo y Previsión Social, Ciudad de México 
Angel-Urdinola DF, Semlali A, Brodmann S (2010) Non-public provision of active labor market programs in ArabMediterranean countries: An inventory of youth programs (SP Discussion Paper No. 1005). World Bank, Washington Attanasio O, Kugler A, Meghir C (2011) Subsidizing vocational training for disadvantaged youth in Colombia: Evidence from a randomized trial. Am Econ J Appl Econ 3(3):188-220

Becker B, Wu MJ (2007) The synthesis of regression slopes in meta-analysis. Stat Sci 22:414-429

Benus J, Rude J, Patrabansh S (2001) Impact of the Emergency Demobilization and Reintegration Project (Prepared for: U.S. Department of Labor Bureau of International Affairs Office of Foreign Relations). http://pdf.usaid.gov/pdf_docs/ Pcaab161.pdf. Accessed 25 Oct 2013

Betcherman G, Olivas K, Dar A (2004) Impacts of active labour market programs: New evidence from evaluations with particular attention to developing and transition countries (Social Protection Discussion Paper Series No. 0402). World Bank, Washington

Betcherman G, Godfrey M, Puerto S, Rother F, Stavreska A (2007) A review of interventions to support young workers: Findings of the youth employment inventory (Social Protection Discussion Paper No. 0715). World Bank, Washington

Bidani B, Goh C, O'Leary CJ (2002) Has training helped employ Xiagang in China? A tale from two cities (Report for the World Bank's Poverty Reduction and Economic Unit East Asia and Pacific Region). World Bank, Washington

Card D, Kluve J, Weber A (2010) Active labour market policy evaluations: A meta-analysis. Econ J 120:F452-F477

Card D, Ibarraran P, Regalia F, Rosas-Shady D, Soares Y (2011) The labor market impacts of youth training in the Dominican Republic. J Labor Econ 29(2):267-300

Chong A, Galdo J (2006) Does the quality of training programs matter? Evidence from bidding processes data (IZA Discussion Paper No. 2202). Institute for the Study of Labor, Bonn

Chong A, Galdo J, Saavedra J (2008) Informality and productivity in the labor market in Peru. J Econ Policy Reform 11(4):229-245

Chun N, Watanabe M (2011) Can skill diversification improve welfare in rural areas? Evidence from the Rural Skills Development Project in Bhutan (ADB Economics Working Paper Series No. 260). Asian Development Bank, Manila

Deeks JJ, Altman DA, Bradburn MJ (2001) Statistical methods for examining heterogeneity and combining results from several studies in meta-analysis. In: Egger M, Davey Smith G, Altman DG (eds) Systematic reviews in health care: Meta-analysis in context. BMJ Publishing Group, London, pp 313-335

Delajara M, Freije S, Soloaga I (2006) An evaluation of training for the unemployed in Mexico (Working Paper: OVENWP09/06). Inter-American Development Bank, Washington

Díaz JJ, Jaramillo M (2006) An evaluation of the Peruvian 'youth labor training program' - Projoven (Working Paper: OVE/WP-10/06). Inter-American Development Bank, Washington

Dmitrijeva J (2009) The employment effects of public training programme: Evidence from Latvian micro and macro data. http://www.univ-orleans.fr/leo/images/espace_commun/seminaires/semmar2009/WP_57.pdf. Accessed 25 Oct 2013

Duvendack M, Hombrados JG, Palmer-Jones R, Waddington H (2012) Assessing 'what works' in international development: meta-analysis for sophisticated dummies. J Dev Eff 4:456-471

Elías VJ, Ruiz Núñez FR, Cossa R, Bravo D (2004) An econometric cost-benefit analysis of Argentina's youth training program (Research Network Working Paper \#R-482). Inter-American Development Bank, Washington

Espinoza H (2010) Impact evaluation of a job-training programme for disadvantaged youths: The case of Projoven. Boekenplan, Maastricht

Fares J, Puerto OS (2009) Towards comprehensive training (Social Protection Discussion Paper No. 0924). World Bank, Washington

Greenberg DH, Michalopoulos C, Robins PK (2003) A meta-analysis of government-sponsored training programs. Ind Labor Relat Rev 57(1):31-53

Hicks JH, Kremer M, Mbiti l, Miguel E (2011) Vocational education voucher delivery and labor market returns: A randomized evaluation among Kenyan youth (Report for Spanish Impact Evaluation Fund (SIEF) Phase II). World Bank, Washington

Higgins JPT, Green S (eds) (2011) Cochrane handbook for systematic reviews of interventions. Wiley-Blackwell, Chichester

Hombrados JG, Waddington H (2012) Internal validity in social experiments and quasi-experiments: An assessment tool for reviewers. Mimeo, London

Ibarraran P, Rosas-Shady D (2006) Impact evaluation of the job training component (PROCAJOVEN) of the assistance program for the building of a training and employment system in Panama (PN0125) (Ex-Post Project Evaluation Report: OVE/EPPER-02/06). Inter-American Development Bank, Washington

International Labour Organization (2011) Global employment trends for youth: 2011 update. International Labour Organization, Geneva

International Labour Organization (2012) Global employment trends 2012: Preventing a deeper jobs crisis. International Labour Organization, Geneva

Jaramillo M, Galdo J, Montalva V (2007) Do the poorest among the poor benefit from active labor market programs? Evidence from Peru's Projoven. http://www.depeco.econo.unlp.edu.ar/cedlas/ien/pdfs/meeting2007/papers/ jaramillo.pdf. Accessed 25 Oct 2013

Katz E (2008) Programs promoting young women's employment: What works? Background paper for Adolescent Girls Initiative. World Bank, Washington

King K, Palmer R (2010) Planning for technical and vocational skills development. UNESCO International Institute for Educational Planning, Paris

Kluve J (2006) The effectiveness of European active labor market policy (IZA Discussion Paper 2018). Institute for the Study of Labor, Bonn

Kluve J, Schmidt C (2002) Can training and employment subsidies combat European unemployment? Econ Policy 35:409-448 Lipsey MW, Wilson D (2001) Practical meta-analysis. Sage, London

López-Acevedo G (2003) A reassessment of technical education in Mexico. J Career Tech Educ 19(2):59-81

Medina C, Nuñez J (2005) The impact of private and public job training in Colombia (Research Network Working Paper \#R-484). Inter-American Development Bank, Washington 
Mensch BS, Grant MJ, Sebastian MP, Hewett PC, Huntington D (2004) The effect of a livelihoods intervention in an urban slum in India: Do vocational counseling and training alter the attitudes and behavior of adolescent girls? (Working Paper No. 194). Population Council, New York

Ñopo H, Robles M, Saavedra J (2007) Occupational training to reduce gender segregation: The impacts of ProJoven (Research Department Working Paper \#623). Inter-American Development Bank, Washington

Papaioannou D, Sutton A, Carroll C, Booth A, Wong R (2009) Literature searching for social science reviews: consideration of a range of search techniques. Health Info Libr J 27:114-122

Péano S, Vergel de Dios B, Atchoaréna D, Mendoza U (2008) Investment in technical vocational education and training (TVET) in the Philippines. International Institute for Educational Planning, Paris

Petrosino A, Morgan C, Fronius TA, Tanner-Smith EE, Boruch RF (2012) Interventions in developing nations for improving primary and secondary school enrollment of children: A systematic review. Campbell Syst Rev 2012:19, DOl: $10.4073 / \mathrm{csr} .2012 .19$

Puerto OS (2007) Interventions to support young workers in Latin America and the Caribbean: Regional report for the Youth Employment Inventory. World Bank, Washington

Rosenbaum PR, Rubin DB (1983) The central role of the propensity score in observational studies for causal effects. Biometrika 70(1):41-55

Schucan Bird K, Tripney J (2011) Systematic literature searching in policy relevant, inter-disciplinary reviews: An example from culture and sport. Res Synth Methods 2(3):163-173

Stavreska A (2006) Interventions to support young workers in South, East Asia and the Pacific: Regional report for the Youth Employment Inventory. World Bank, Washington

Tripney J, Newman M, Hovish K, Brown C (2012) Protocol: Post-basic technical and vocational education and training (TVET) interventions to improve employability and employment of TVET graduates in low- and middle-income countries. http://campbellcollaboration.org/lib/project/227/. Accessed 25 Oct 2013

Tripney J, Hombrados J, Newman M, Hovish K, Brown C, Steinka-Fry K, Wilkey E (2013) Technical and vocational education and training (TVET) interventions to improve the employability and employment of young people in low- and middle-income countries: A systematic review. Campbell Syst Rev 2013:9, DOl: 10.4073/csr.2013.9

United Nations (2012) World youth report. United Nations, Geneva

United Nations Educational, Scientific and Cultural Organization (2010) Reaching the marginalised. Education for All Global Monitoring Report 2010. UNESCO, Paris

United Nations Educational, Scientific and Cultural Organization (2012) Youth and skills: Putting education to work. Education for All Global Monitoring Report 2012. UNESCO, Paris

Van Adams A (2007) The role of youth skills development in the transition to work: A global review (HDNCY No. 5). World Bank, Washington

van Gameren E (2010) Evaluación de impacto del programa de apoyo al empleo. Secretaría de Trabajo y Previsión Social (STPS), Ciudad de México

doi:10.1186/1877-6345-5-3

Cite this article as: Tripney and Hombrados: Technical and vocational education and training (TVET) for young people in low- and middle-income countries: a systematic review and

meta-analysis. Empirical Research in Vocational Education \& Training 2013 5:3.

\section{Submit your manuscript to a SpringerOpen ${ }^{\circ}$ journal and benefit from:}

- Convenient online submission

- Rigorous peer review

- Immediate publication on acceptance

- Open access: articles freely available online

- High visibility within the field

Retaining the copyright to your article

Submit your next manuscript at $\boldsymbol{\sim}$ springeropen.com 